\title{
Comparative genomics and expression profile of lipid biosynthesis pathway genes in Camellia
} sinensis

\section{Madhurjya Gogoi * , Afruza Zaman ${ }^{\#}$, Sangeeta Borchetia and Tanoy Bandyopadhyay}

Supplementary Table S1. List of primer sequence designed from the five lipid biosynthesis genes of Camellia sinensis for quantitative Real Time-PCR analysis.

\begin{tabular}{|l|l|l|}
\hline Gene Name & $\begin{array}{l}\text { Camellia sinensis } \\
\text { Contig (C)/ } \\
\text { Singleton(S) }\end{array}$ & Primer sequence \\
\hline $\begin{array}{l}\text { Biotin carboxylase } \\
\text { (Heteromeric Acetyl- } \\
\text { CoA carboxylase) (BC) }\end{array}$ & C2 & $\begin{array}{l}\text { Forward- 5' ACTCGAATCCAGGTTGAGCA 3' } \\
\text { Reverse- 5' TGTTATTCTCCCTGGCCCAG 3' }\end{array}$ \\
\hline $\begin{array}{l}\text { Acyl CoA: } \\
\text { diacylglycerol } \\
\text { acyltransferase (DGAT) }\end{array}$ & S1 & $\begin{array}{l}\text { Forward- 5' TTCAGTTTTGCCCATCGGTG 3', } \\
\text { Reverse- 5' GCCATGTCCATATGTGCCTG 3' }\end{array}$ \\
\hline $\begin{array}{l}\text { Phosphatidylinositol } \\
\text { synthase (PIS) }\end{array}$ & C1 & $\begin{array}{l}\text { Forward- 5' TCTGTGATGCCTTGGATGGT 3' } \\
\text { Reverse- 5' ACATCTGCAACCAATGGCTG 3' }\end{array}$ \\
\hline $\begin{array}{l}\text { Monogalactosyldiacylgl } \\
\text { ycerol synthase } \\
\text { (MGDGS) }\end{array}$ & C2 & $\begin{array}{l}\text { Forward- 5' CAACCCATTAGCATCACCCG 3', } \\
\text { Reverse- 5' GTTGGTGAGAAGAGACCCCA 3' }\end{array}$ \\
\hline $\begin{array}{l}\text { Glycerol-3-phosphate } \\
\text { dehydrogenase } \\
\text { (G3PDH) }\end{array}$ & C2 & $\begin{array}{l}\text { Forward- 5' GGGCAAAGTGGTGTGTCAAT 3', } \\
\text { Reverse- 5' GACAGCCGAGCACCTATTTG 3' }\end{array}$ \\
\hline
\end{tabular}

